\title{
Effect of microstructure and residual stresses, generated from different annealing and deformation processes, on the corrosion and mechanical properties of gold welding alloy wires
}

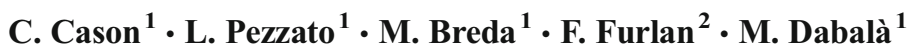

Published online: 10 November 2015

(C) The Author(s) 2015. This article is published with open access at SpringerLink.com

\begin{abstract}
Gold welding alloys, which are used in the production of both hollow and solid gold chains, affect the optical and mechanical properties of various gold products because the corrosion resistance of the individual links depends on these properties. It is important that welding alloys with high corrosion resistance do not degrade during or after the production process. The mechanical properties of gold welding alloy wires are strongly influenced by the alloy microstructure, which has a key role in both the machinability and the quality of the wires. In the presented work, various physical and mechanical properties of gold originating from different industrial deformation processes are evaluated. Specifically, various plastic deformation grades caused by different annealing and rolling steps are analyzed. The change of the temperature, time, and velocity parameters in the annealing and lamination processes leads to the formation of different levels of residual stresses in the material, which can generate a variation in the corrosion properties of the gold wires. The change in microstructure, due to the different annealing and rolling steps, is analyzed by optical microscope (OM) and SEM observations. The residual stresses are evaluated using XRD analysis, and the variations of the mechanical properties by micro-hardness tests. The corrosion resistance is evaluated by potentiodynamic polarization tests, in which an electrolyte solution is used to simulate human sweat. Small grain size and high homogeneity of the microstructure are preferred for the final products. In
\end{abstract}

C. Cason

claudio.cason.1@studenti.unipd.it

1 Department of Industrial Engineering, University of Padua, Via Marzolo 9, 35131 Padova, Italy

2 Filk S.p.A., Via Dell'industria 8, 36065 Mussolente, VI, Italy this study, the samples that have been produced are shown to have lower levels of residual stresses and feature higher corrosion resistance and more favorable mechanical properties.

Keywords Gold alloy wires · Gold welding · Corrosion resistance $\cdot$ Residual stress

\section{Introduction}

The consumer demand for gold has, until recently, been entirely driven by the jewelry market, which represented the most common use of this precious metal. Recently, there has been a quick rise in the demand of gold for other uses, which has reduced the impact of jewelry in the global gold market to about $45 \%$ of the total demand. Besides the demand due to the finance and investment sector, which constitutes approximately $45 \%$ of the market, the remaining $10 \%$ of the demand is due to technological and industrial applications. The physical and mechanical characteristics of gold, as well as its other properties (such as malleability, nobility, ductility, and shine), make it attractive as a material for use in jewelry. Two major categories of carat gold alloy for jewelry exist: "colored gold alloys," which are alloys based on a gold-silver-copper or a gold-silver copper-zinc system, and the "white gold alloys." Regardless of the zinc content, colored gold alloys with less than $15 \%$ zinc by weight can all be considered to be similar to the gold-silver-copper ternary system, because all such alloys demonstrate the same metallurgical characteristics [1].

The production of gold-based jewelry items starts with the melting process of ingots or with a continuous casting of gold alloy wires in order to create rings, chains, bracelets, and similar items. After this primary step, the material undergoes alternating mechanical deformations and recrystallization annealing treatments. The progressive mechanical deformation 
Table 1 Chemical compositions of the yellow welding alloys that were studied

\begin{tabular}{llllc}
\hline $\mathrm{Kt}$ & $\mathrm{Au}(\%)$ & $\mathrm{Cu}(\%)$ & $\mathrm{Ag}(\%)$ & $\mathrm{Zn} \mathrm{( \% )}$ \\
\hline 14 & 58.5 & 18.6 & 17.1 & 5.8 \\
10 & 41.7 & 23.6 & 17.6 & 17.1 \\
9 & 37.5 & 29.1 & 15.1 & 18.3 \\
\hline
\end{tabular}

modifies the structure of the metal while work hardening increases inversely to the ductility of the metal [2]. To further facilitate working, the malleability of the semi-finished product can be restored by an annealing process in a static or belt furnace for an appropriate time and temperature. During this process, the strained microstructure of the gold alloys is replaced by a lower potential energy and more workable microstructure.

The thermally activated phenomenon of recrystallization is most easily achieved through a sustained period of a constant high temperature. However, other phenomena can concurrently take place in multi-component gold alloys with the recrystallization. Some of the phenomena are beneficial, such as homogenization of both macro and micro segregations, while other effects, such as precipitation of secondary phase or excessive grain growth, are undesirable. Gold alloys recrystallize achieving finer grains proportionally with the grades of deformation, a behavior that is dependent on the amount of potential energy stored within the structure. Small grain size is preferred in order to reduce or avoid the superficial "orange peel" effect.

An optimal choice of the parameters in the annealing process is important in order to control the re-ordering of the alloy's microstructure or the precipitation of secondary phases [3]. This can be guaranteed by using a temperature above the ordering or immiscibility field of the alloy system and by a rapid quenching from the annealing temperatures.

The presented work will correlate the microstructural and mechanical characteristics of gold alloys employed for welding wires, with the stress states generated through the sequential steps of deformation and annealing processes. Moreover, the influence of these residual stresses on the corrosion resistance of the welding is studied, since it represents a fundamental characteristic that guarantees suitable properties in a gold chain's final environment of use. The most important phenomenon characterizing the corrosion of gold alloys is the selective dissolution of the less noble elements [4, 5].

Table 2 Parameters used in the XRD analysis

\begin{tabular}{llllll}
\hline Material & $\begin{array}{l}\text { Lattice } \\
\text { structure }\end{array}$ & Symmetry & $\begin{array}{l}\text { Diffraction } \\
\text { plane }\end{array}$ & $\begin{array}{l}\text { Radiation } \\
\text { type }\end{array}$ & $\begin{array}{l}\text { Collimator } \\
\text { diameter }\end{array}$ \\
\hline Gold alloy & FCC & Fm3m & $(220)$ & CuK $\alpha$ & $4 \mathrm{~mm}$ \\
\hline
\end{tabular}

Table 3 Melting and annealing process parameters for two different production paths for the 9-Kt gold alloy

\begin{tabular}{lll}
\hline & Old process & New process \\
\hline Crucible temperature & $930\left({ }^{\circ} \mathrm{C}\right)$ & $930\left({ }^{\circ} \mathrm{C}\right)$ \\
Mold temperature & $640\left({ }^{\circ} \mathrm{C}\right)$ & $640\left({ }^{\circ} \mathrm{C}\right)$ \\
Melting velocity & $6(\mathrm{~mm} / \mathrm{s})$ & $6(\mathrm{~mm} / \mathrm{s})$ \\
Working time & $1.8 \mathrm{~s}$ & $1.8 \mathrm{~s}$ \\
Pause time & $1.4 \mathrm{~s}$ & $1.4 \mathrm{~s}$ \\
Time before quenching & $60 \mathrm{~s}$ & $0 \mathrm{~s}$ \\
Annealing temperature & $610\left({ }^{\circ} \mathrm{C}\right)$ & $600\left({ }^{\circ} \mathrm{C}\right)$ \\
Annealing time & $30(\mathrm{~min})$ & $45(\mathrm{~min})$ \\
Time before quenching & $60(\mathrm{~s})$ & $0(\mathrm{~s})$ \\
\hline
\end{tabular}

\section{Experimental procedure}

Measurements of the melting and annealing parameters for three different welding alloys have been performed. Their respective compositions are shown in Table 1. Several tests were implemented in order to optimize the continuous melting and the annealing processes. In particular, microstructural analyses and hardness tests were performed, in which the temperatures, time of melting and quenching, and velocity of melting and rolling are the relevant parameters.

First results obtained by optical microscope (OM) analysis were used to modify some production parameters. The melting temperature in the crucible was increased in order to optimize manual and induction mixing. The same conditions were created in the mold with the aim of maintaining a good solubility of the low-melting elements. The number of water jets, in the continuous casting operation, was increased in order to homogenize the system of cooling out of the furnace. As the cooling time in air before the water quenching was suppressed, the jets of water were moved to a zone closer to the mold's exit.

After solidification, the cross section of the rods was reduced from about $6.00 \mathrm{~mm}$ to a diameter of $1.00 \mathrm{~mm}$, by applying the sequential steps of rolling, annealing, and final drawing. A similar investigation was performed for the annealing process in the static furnace. Time, temperature, and cooling parameters were modified in order to improve the resistance of the wires during rolling steps and with the aim

Table 4 Micro-Vickers hardness for the final annealed wires obtained with the two different production paths for the 9-Kt gold alloy

\begin{tabular}{lll}
\hline & & $\begin{array}{l}\text { Micro-hardness } \\
\left(\mathrm{HV}_{0.025}\right)\end{array}$ \\
\hline $\begin{array}{ll}1.00-\mathrm{mm} \text { diameter } \\
\text { final annealed wire }\end{array}$ & Old process & $202 \pm 5$ \\
& New process & $175 \pm 5$ \\
\hline
\end{tabular}


Fig. 1 Microstructure of the gold alloy wire obtained with the new optimized process for the final drawn step (a) and after the last annealing process in the static furnace (b)
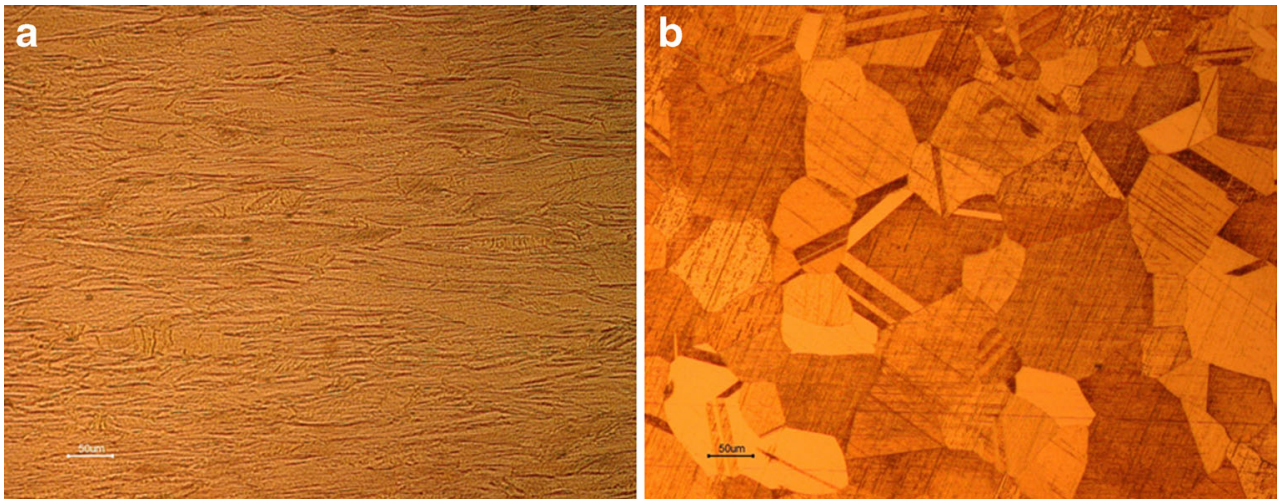

of obtaining a satisfactory recrystallization after deformation. A statistical analysis on different annealing tests at various temperatures (from 560 to $610{ }^{\circ} \mathrm{C}$ ), times (30 and $45 \mathrm{~min}$ ), and air cooling (from 0 to $60 \mathrm{~s}$ ) showed that it is possible to reduce the hardness with suitable heat treatments. To evaluate the mechanical properties of the final annealed products, tensile and hardness tests were performed using an INSTRON testing system and a LEITZ microdurometer with a Vickers penetrator set with a $25-\mathrm{g}$ load and with $30 \mathrm{~s}$ of loading time. An OM observation was performed with a LEICA DMRE microscope. The samples were prepared with the standard metallographic technique of polishing and the etch was performed with different solutions of cyanide.

The corrosion resistance was evaluated with potentiodynamic polarization tests, using as electrolyte a solution that simulates human sweat in order to replicate the environment of final use. By mass, the solution consisted of $0.5 \% \mathrm{NaCl}$, $0.1 \%$ lactic acid, and $0.1 \%$ urea. A solution of $\mathrm{NaOH}$ was used to guarantee an acidity of $\mathrm{pH} 6.5$. Anodic polarization tests were performed with an AMEL 2549 Potentiostat, using a saturated calomel electrode (SCE) as the reference electrode and a platinum electrode as the counter electrode with a scan
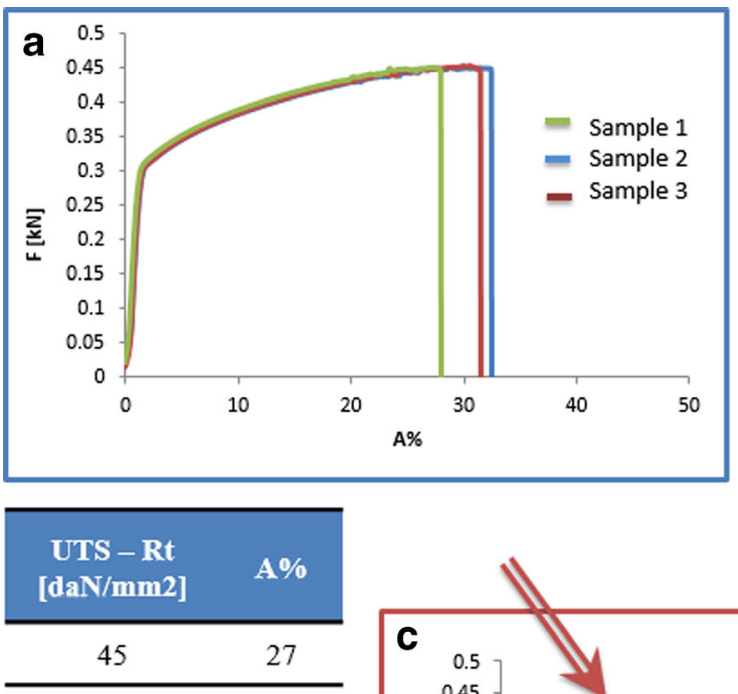
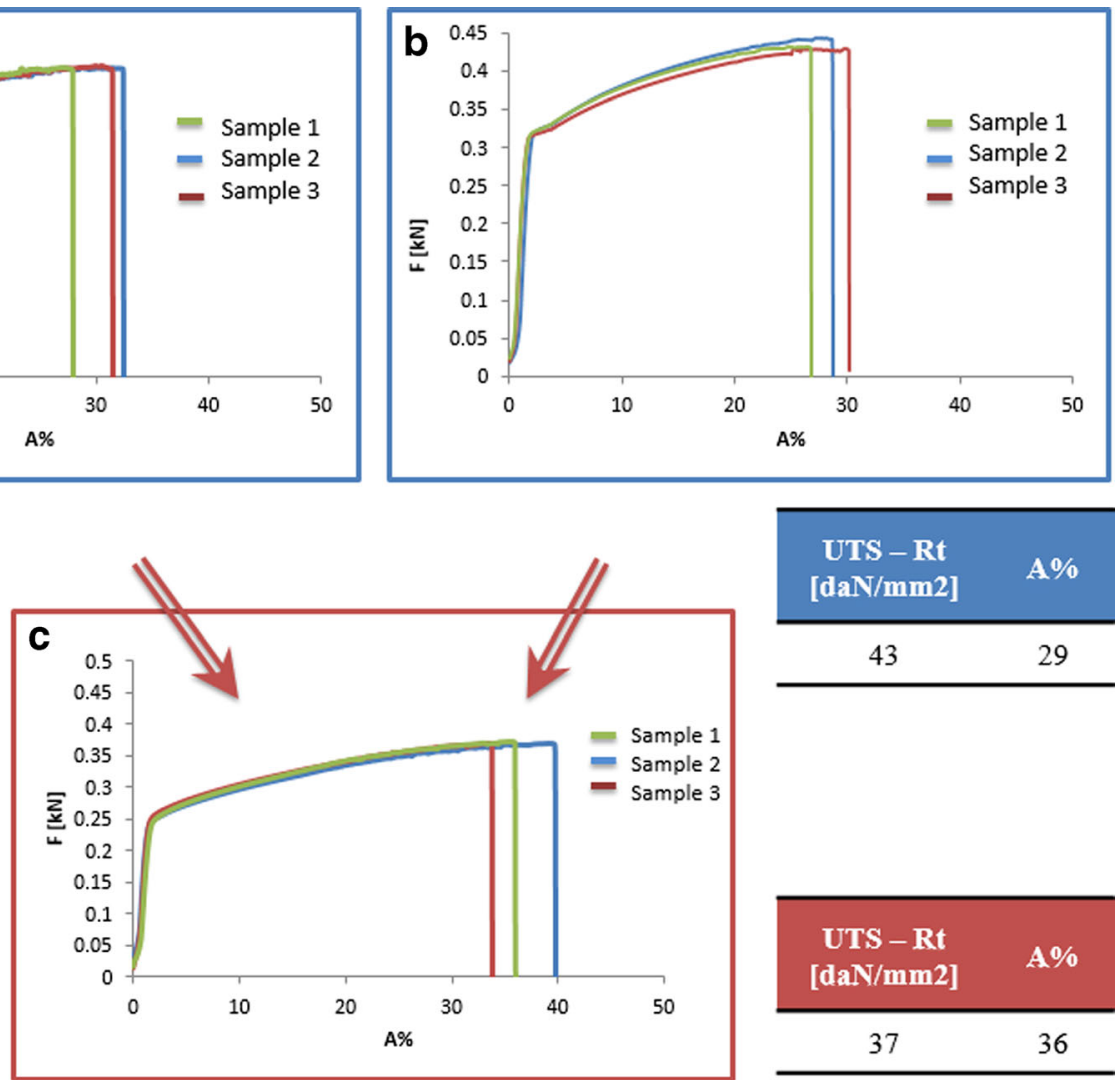

Fig. 2 Tensile curves and the average values of strength and elongation for the final annealed wires obtained with the old process $(\mathbf{a}, \mathbf{b})$ and the new one (c) 
Table 5 Melting and annealing process parameters for two different production paths for the 10-Kt gold alloy

\begin{tabular}{lll}
\hline & Old process & New process \\
\hline Crucible temperature & $930\left({ }^{\circ} \mathrm{C}\right)$ & $930\left({ }^{\circ} \mathrm{C}\right)$ \\
Mold temperature & $640\left({ }^{\circ} \mathrm{C}\right)$ & $640\left({ }^{\circ} \mathrm{C}\right)$ \\
Melting velocity & $6(\mathrm{~mm} / \mathrm{s})$ & $3.5(\mathrm{~mm} / \mathrm{s})$ \\
Working time & $1.8 \mathrm{~s}$ & $1.2 \mathrm{~s}$ \\
Pause time & $1.4 \mathrm{~s}$ & $1.0 \mathrm{~s}$ \\
Time before quenching & $60 \mathrm{~s}$ & $0 \mathrm{~s}$ \\
Annealing temperature & $610\left({ }^{\circ} \mathrm{C}\right)$ & $600\left({ }^{\circ} \mathrm{C}\right)$ \\
Annealing time & $30(\mathrm{~min})$ & $45(\mathrm{~min})$ \\
Time before quenching & $60(\mathrm{~s})$ & $0(\mathrm{~s})$ \\
\hline
\end{tabular}

rate of $8 \times 10^{-4} \mathrm{~V} / \mathrm{s}$. A Cambridge Stereoscan 440 scanning electron microscope equipped with a Philips PV9800 EDS was used, in order to study the microstructures obtained from the variation in processing parameters. The residual stresses were evaluated using a Siemens D500 X-ray diffractometer using $\mathrm{CuK} \alpha$ radiation. The operating parameters for the XRD measurement are shown in Table 2.

\section{Results and discussion}

During the microstructural and mechanical analysis, several different process parameters of the production cycle were tested for different welding alloys. The aim was to identify the relationship between the parameters of the processes, the microstructures, and the mechanical qualities of the semifinished products. Furthermore, the influence of these characteristics on the residual stresses and the corrosion resistance was evaluated. In this work, three different carat gold alloys were considered, 9, 10, and $14 \mathrm{Kt}$.

\section{$9 \mathrm{Kt}$}

An analysis of the lowest commercial carat gold alloy allows the possibility to attempt to reproduce the results observed for
Table 6 Micro-Vickers hardness for the final annealed wires obtained with the two different production paths for the 10-Kt gold alloy

\begin{tabular}{lll}
\hline & & $\begin{array}{l}\text { Micro-hardness } \\
\left(\mathrm{HV}_{0.025}\right)\end{array}$ \\
\hline $\begin{array}{c}1.00-\mathrm{mm} \text { diameter } \\
\text { final annealed wire }\end{array}$ & Old process & $190 \pm 10$ \\
& New process & $175 \pm 10$ \\
\hline
\end{tabular}

the other carat gold welding alloys, by optimizing the entire production cycle. The two different processes for the 9-Kt gold alloys are shown in Table 3 . The deformation cycles are the same as in the 10- and 14-Kt gold weldings. An immediate cooling of the wires between the melting and the annealing furnaces allowed for the hardness of the gold alloy to be reduced, as shown in Table 4. Immediate cooling also allows for an increase in the malleability and the workability during rolling, drawing, and in the chain production machines. The microstructures of the final annealed, and previously deformed, samples obtained with the new production processes are shown in Fig. 1. In Fig. 1a, the slip bands due to plastic deformation are shown, while in Fig. 1b, it is shown how the annealing process allows for the restoration of the fine grain microstructure. The tensile tests indicated a considerable increase in the elongation for the final annealed wires obtained after the change in the parameters of the whole production process, as shown in Fig. 2.

\section{$10 \mathrm{Kt}$}

For low-carat gold and gold welding alloys such as the 9- and 10-Kt samples, the addition of zinc has an important effect on the properties of the material. Zinc causes a reduction in the volume of the immiscibility field, and this affects processes such as annealing, solution annealing, susceptibility to softening or overageing, and temperature of precipitation hardening. The presence of a higher fraction of less noble elements, in comparison with the 14-Kt sample, increases the fragility and the sensitivity to ruptures in the solidification phase during the melting process.
Fig. 3 Microstructures of the annealed wires obtained with the two different processes, the old (a) and the optimized one (b), at the end of the production cycle
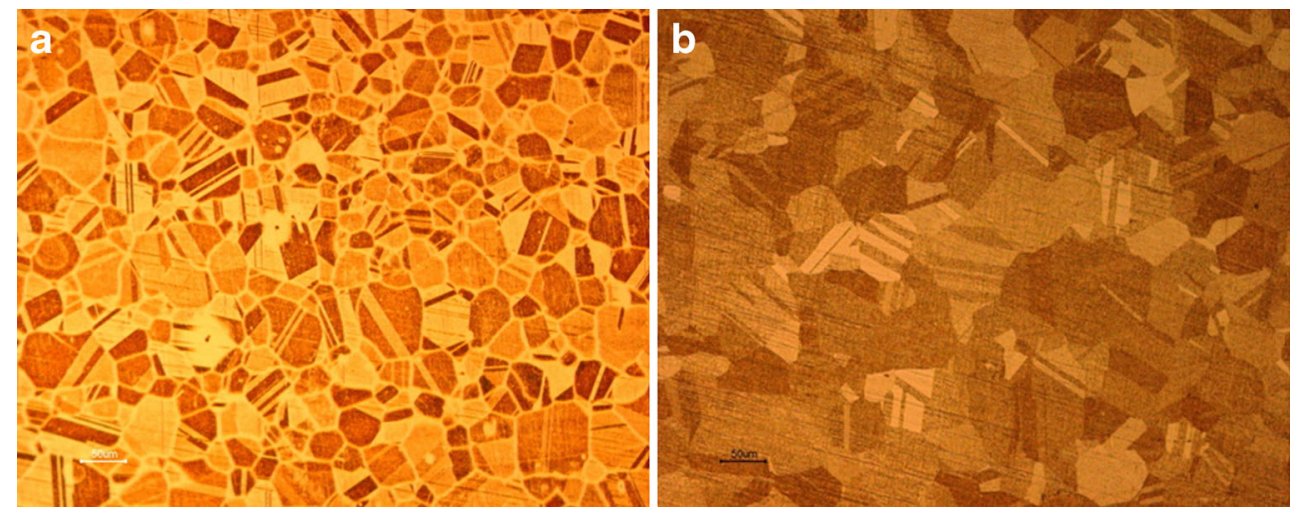


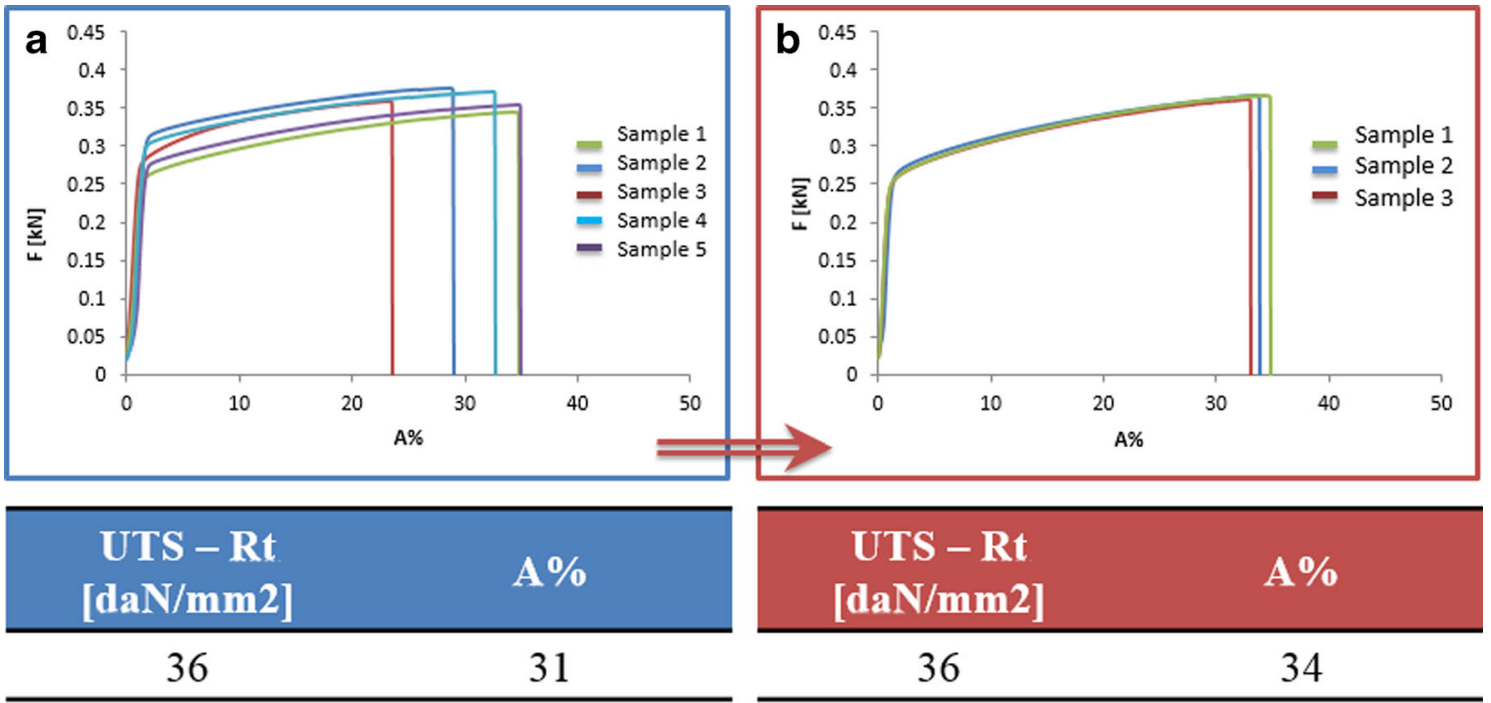

Fig. 4 Tensile curves and the average values of strength and elongation for the final annealed wires obtained with the old process (a) and the new one (b)

In order to reduce stresses generated from the solidification phase and the superficial interaction between the rod and the graphite mold, the velocity of melting, the total time of work and pause of the rollers downline of the crucible, and the time before quenching were reduced, as indicated in Table 5. The microstructures resulting from the optimization demonstrated a greater homogeneity and a non-negligible decrease in the hardness of the melting specimens. The immediate cooling of the rod after the melting furnace allows one to maintain a smaller grain size than obtained in previous production processes. A similar procedure was followed for the microstructures of the samples at the end of the production process, as shown in Fig. 3. Although the hardness remained approximately constant in the final annealed wire specimens during the annealing process, as shown in Table 6, the decrease in temperature and the increase in time of the treatment allow one to avoid precipitation phenomena, ensuring that a singlephase material is produced with a uniform distribution of grain

Table 7 Melting and annealing process parameters for three different production paths for the 14-Kt gold alloy

\begin{tabular}{llll}
\hline & Process 1 & Process 2 & Process 3 \\
\hline Crucible temperature & $930\left({ }^{\circ} \mathrm{C}\right)$ & $930\left({ }^{\circ} \mathrm{C}\right)$ & $930\left({ }^{\circ} \mathrm{C}\right)$ \\
Mold temperature & $640\left({ }^{\circ} \mathrm{C}\right)$ & $640\left({ }^{\circ} \mathrm{C}\right)$ & $640\left({ }^{\circ} \mathrm{C}\right)$ \\
Melting velocity & $6(\mathrm{~mm} / \mathrm{s})$ & $6(\mathrm{~mm} / \mathrm{s})$ & $3.5(\mathrm{~mm} / \mathrm{s})$ \\
Working time & $1.8 \mathrm{~s}$ & $1.8 \mathrm{~s}$ & $1.2 \mathrm{~s}$ \\
Pause time & $1.4 \mathrm{~s}$ & $1.4 \mathrm{~s}$ & $1.0 \mathrm{~s}$ \\
Time before quenching & $60 \mathrm{~s}$ & $0 \mathrm{~s}$ & $0 \mathrm{~s}$ \\
Rolling velocity & $35 \mathrm{~m} / \mathrm{min}$ & $35 \mathrm{~m} / \mathrm{min}$ & $20 \mathrm{~m} / \mathrm{min}$ \\
Annealing temperature & $610\left({ }^{\circ} \mathrm{C}\right)$ & $560\left({ }^{\circ} \mathrm{C}\right)$ & $600\left({ }^{\circ} \mathrm{C}\right)$ \\
Annealing time & $30(\mathrm{~min})$ & $45(\mathrm{~min})$ & $30(\mathrm{~min})$ \\
Time before quenching & $60(\mathrm{~s})$ & $0(\mathrm{~s})$ & $0(\mathrm{~s})$ \\
\hline
\end{tabular}

dimensions. This improvement in the uniformity of the microstructure leads to an improvement of the mechanical properties, as shown in Fig. 4.

\section{$14 \mathrm{Kt}$}

In the case of the 14-Kt sample, three different production processes were implemented using the parameters indicated in Table 7. The microstructures of the final annealed wires obtained with the first two processes and the deformed and annealed microstructures for the samples treated with the third optimized process (process 3 ) are shown in Fig. 5.

The comparison of the microstructures shows a refining of grain size and a greater homogeneity for the specimen obtained with process 3 . In particular, by employing process 3 , the grain size is shown to be very fine. To better understand the structure in these samples, SEM analyses were performed. Figure 6 shows the SEM microstructures analyzed with backscattered electrons. This change in the structure of the material causes a significant decrease in the hardness of the specimens derived from process 3 . The corresponding data are reported in Table 8. The optimization of the annealing steps in process 3 led to a more regular growth of the grains and a large reduction of the grain size in the final annealed wire. As for the other welding alloys, this was achieved by a decrease in the temperature by about $10{ }^{\circ} \mathrm{C}$ and by the immediate cooling after removal from the furnace, which avoid undesirable grain growth.

The air cooling time is a critical variable in the process, as the hardness of the gold wire decreases due to cooling in water immediately after the furnace. Hardness can therefore be used to quantify the role of air cooling, as the rearrangement of the atoms in the crystal lattice gives the material a greater hardness due to the transition from a disordered distribution to an 
Fig. 5 Microstructures of the $1.00-\mathrm{mm}$ final annealed wires obtained with process 1 (a) and process 2 (b). Rolled and final annealed microstructures of the sample made through the optimization of the production parameters with process 3 , respectively (c) and (d)
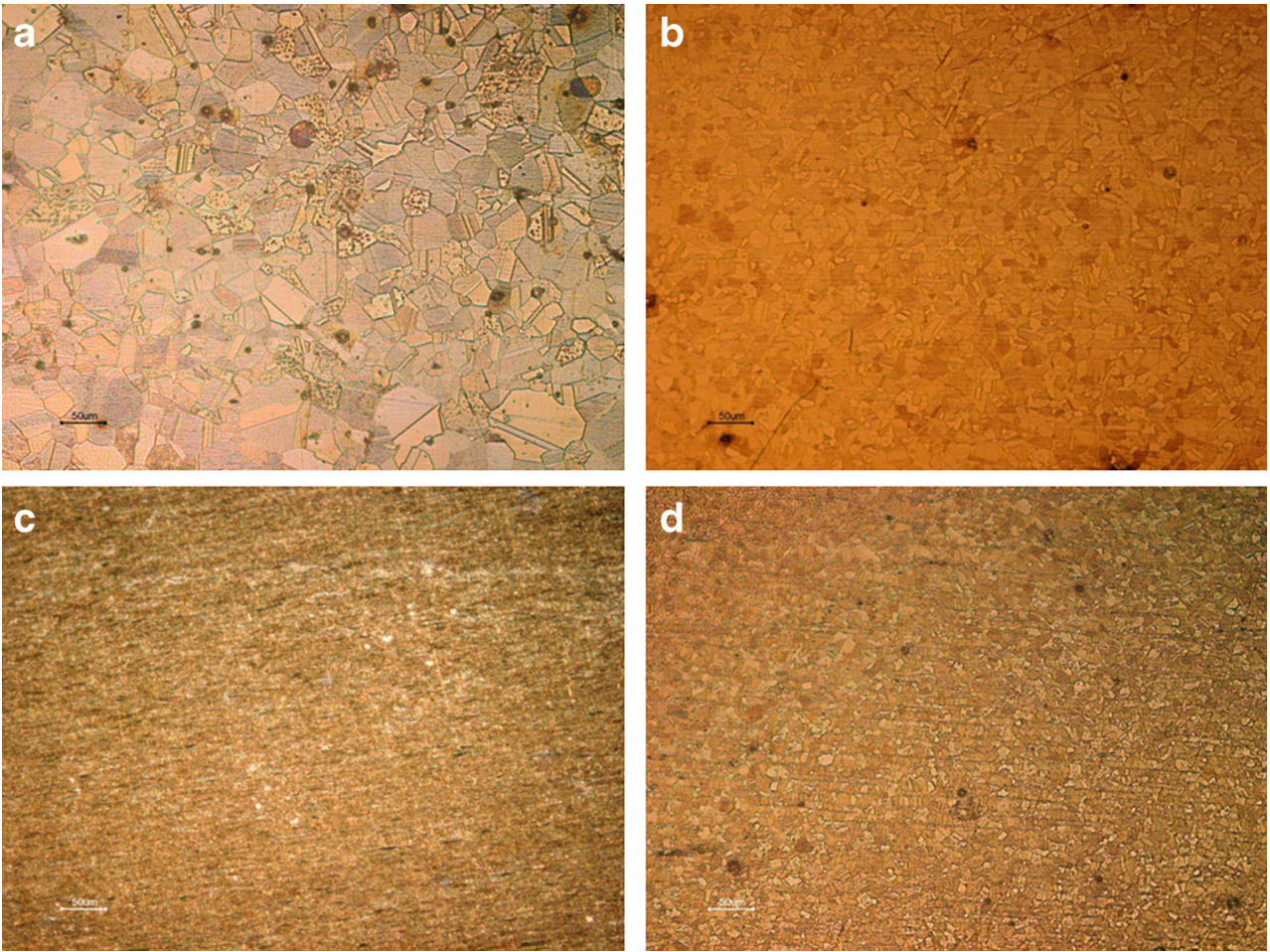

ordered one. In Fig. 7, the tensile tests show a degree of uniformity in the relationship between elongation and the tensile stress of the specimens taken from the skeins of wire produced by process 3 . As observed in the previous process, the values of strength and elongation in the same skein showed a significant variation, which demonstrates the presence of crystallized and non-crystallized zones.
As previously reported, the corrosion of gold alloys starts with a selective dissolution of the less noble species (particularly in welding alloys which are rich in such elements) and ends with the formation of superficial oxides and their decomposition [6]. Mass transport, defined as the volume diffusion from the bulk to the superficial layers of the material, is an important phenomenon as it leads to the exposure of more
Fig. 6 SEM micrographs obtained with backscattered electrons diffraction of the final annealed wires for the old process (a) and those deformed (b) and annealed (c) for the last optimized process
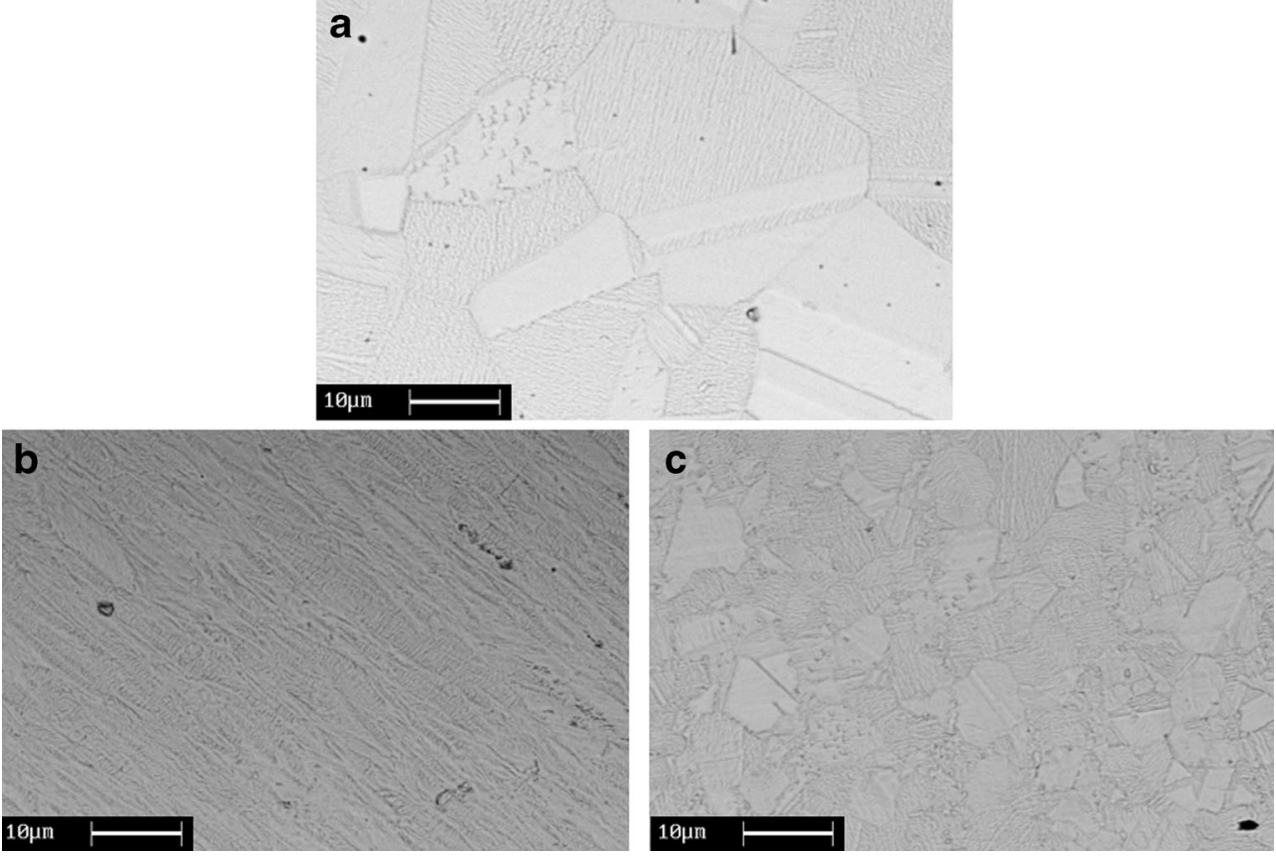
Table 8 Micro-Vickers hardness for the final annealed wires obtained with the three different production paths for the 14-Kt gold alloy

\begin{tabular}{lll}
\hline & & $\begin{array}{l}\text { Micro-hardness } \\
\left(\mathrm{HV}_{0.025}\right)\end{array}$ \\
\hline $\begin{array}{ll}\text { 1.00-mm diameter } \\
\text { final annealed wire }\end{array}$ & Process 1 & $210 \pm 10$ \\
& Process 2 & $175 \pm 10$ \\
& Process 3 & $155 \pm 5$ \\
\hline
\end{tabular}

dissolvable species at the surface. This flow of atoms can be represented by an interior flux of lattice vacancies created by the dissolution of individual atomic sites on the surface of the alloys [7]. Generally, gold alloys, near the equiatomic composition, form a face-centered cubic (FCC) lattice rather than a face-centered tetragonal (FCT) lattice. However, above $683 \mathrm{~K}$ $\left(410^{\circ} \mathrm{C}\right)$, two ordered crystallographic structures (AuCuI and $\mathrm{AuCuII})$ exist [8]. When the $\mathrm{AuCuI}$ ordering prevails in the alloy, the arrangement of the atoms passes from FCC to FCT which generates a considerable amount of strain as a result of the distortion of crystal lattice [9]. These stresses lead to a decrease in the corrosion resistance of the material. The transition from the compact cubic structure to the tetragonal one allows the less noble elements to migrate across the surface easily, which therefore increases the rate of volume diffusion.
In this study, the correlation between the residual stresses, resulting from the specific process parameters of the production cycles of gold wires and their corrosion resistance, was analyzed. The correlation between the decrease of the corrosion resistance and the increase of the tensile state can be found in literature for steels and other materials, but not for gold $[10,11]$. The residual stresses were calculated using $\mathrm{X}$ ray diffraction. The strain in the crystal lattice was measured and the combined residual stresses were defined from the elastic constants. A linear elastic distortion of the crystal lattice planes was assumed. Several grains contributed to the measurements. The number of grains in each sample depended on the size of each grain and on the geometry of the X-ray beam [12]. The penetration depth of the beam depends on the material and on the parameters of the sample. Effectively, the measured strain is the average from depths less than a few microns under the surface of the specimens. Considering a crystalline material, the planes of atoms can cause interference diffraction patterns; this interference is dependent on the spacing between the planes and the wavelength of the incident beam. A free strain material is characterized by a particular diffraction pattern dependent on a determined inter-planar spacing. The elongation and contraction produced during the deformation process of the gold wires generate internal strains in the crystal lattice which change the spacing
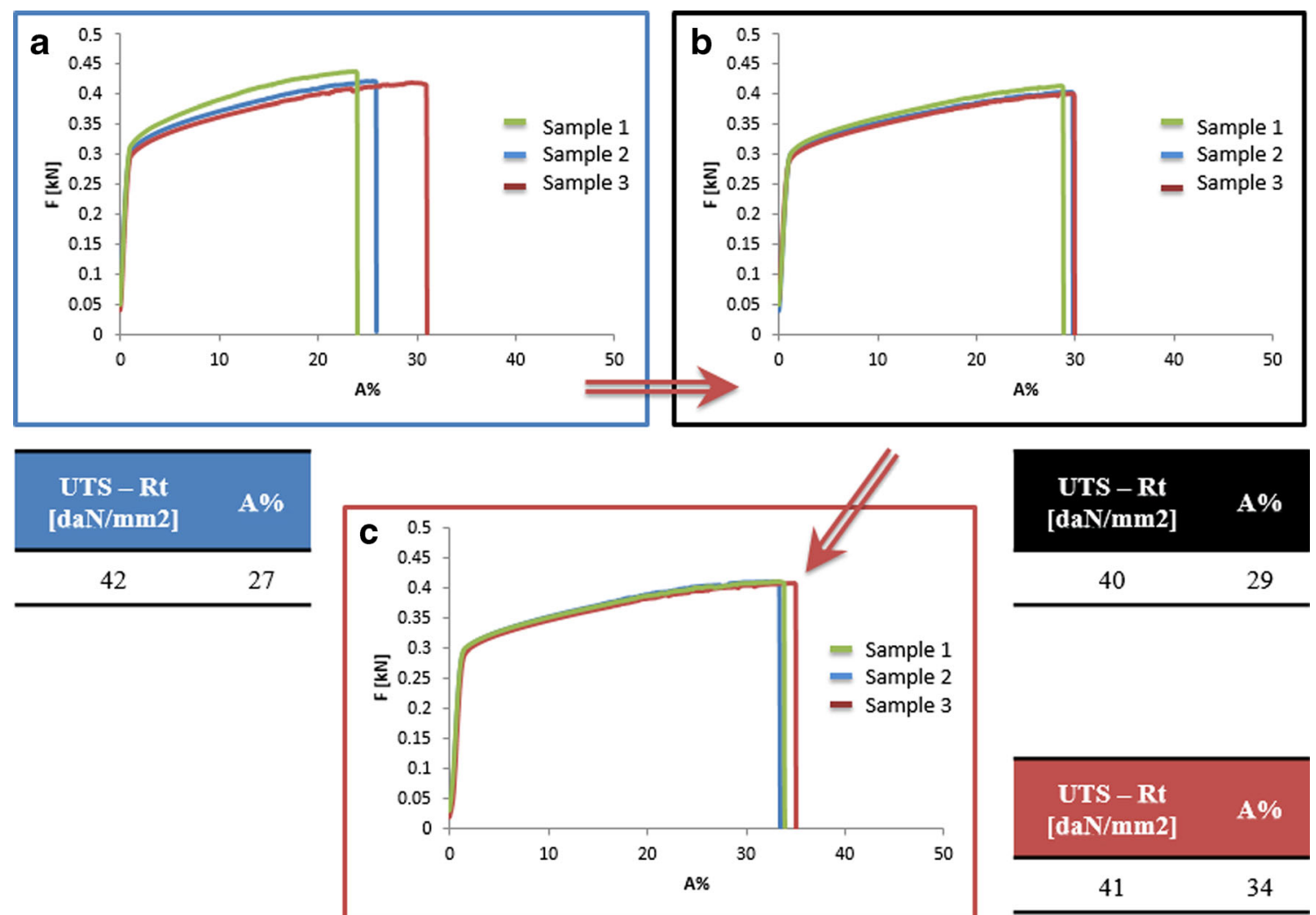

Fig. 7 Tensile curves and the average values of strength and elongation for the final annealed wires obtained with process 1 (a), process 2 (b), and process 3 (c) 
between the $\{\mathrm{hkl}\}$ lattice planes. This results in a measurable shift and broadening of the diffraction pattern, due to a shift from the "free strain" position. This change in the inter-planar spacing can be evaluated in order to define the residual stress within the material [13]. Figure 8 shows the diffraction patterns of the gold alloys that have been studied. For the 9-, 10-, and 14-Kt gold alloys, reference angles of $68.61^{\circ}, 68.16^{\circ}$, and $67.35^{\circ}$ were used, respectively.

The XRD analysis showed that the corrosion behavior of the gold wires depends not only on the specific process parameters but also on the stress state of the material and, in particular, is connected to the residual stresses. Table 9 shows the residual stresses obtained by XRD. It should be noted that there is a considerable difference in the value of the residual stresses for the 9-Kt gold alloy specimens when obtained by implementing the new process. After the final step of rolling, the surface tension of the wire was in a tensile state. The optimization of the annealing treatments changed this to a compression state. The greater homogeneity of the annealed material and the compressive strength of the wire resulted in a better corrosion resistance, as this study will demonstrate. To
Table 9 Residual stresses of all carat gold alloy samples that were studied

\begin{tabular}{ll}
\hline 9-Kt gold alloy deformed (new process) & $\sigma=49 \pm 6 \mathrm{Mpa}$ \\
9-Kt gold alloy annealed (new process) & $\sigma=-227 \pm 26 \mathrm{Mpa}$ \\
10-Kt gold alloy annealed (old process) & $\sigma=158 \pm 66 \mathrm{Mpa}$ \\
10-Kt gold alloy annealed (new process) & $\sigma=-51 \pm 29 \mathrm{Mpa}$ \\
14-Kt gold alloy deformed (new process) & $\sigma=229 \pm 97 \mathrm{Mpa}$ \\
14-Kt gold alloy annealed (new process) & $\sigma=120 \pm 29 \mathrm{Mpa}$ \\
\hline
\end{tabular}

evaluate the difference between the first process and the optimized one for the 10-Kt gold welding alloy, the final annealed microstructures of the specimens obtained with the two processes were tested. It is possible to analyze the different stress states generated by the different optimizations in the final step of wire production cycle. The change of the internal stress from a tensile superficial stress, achieved with the old process, to a compressive stress, obtained with the new process, resulted in an improvement of material's properties. The considerations regarding the 14-Kt gold alloy are the same as the $9-\mathrm{Kt}$ gold welding alloy. The greater homogeneity of the
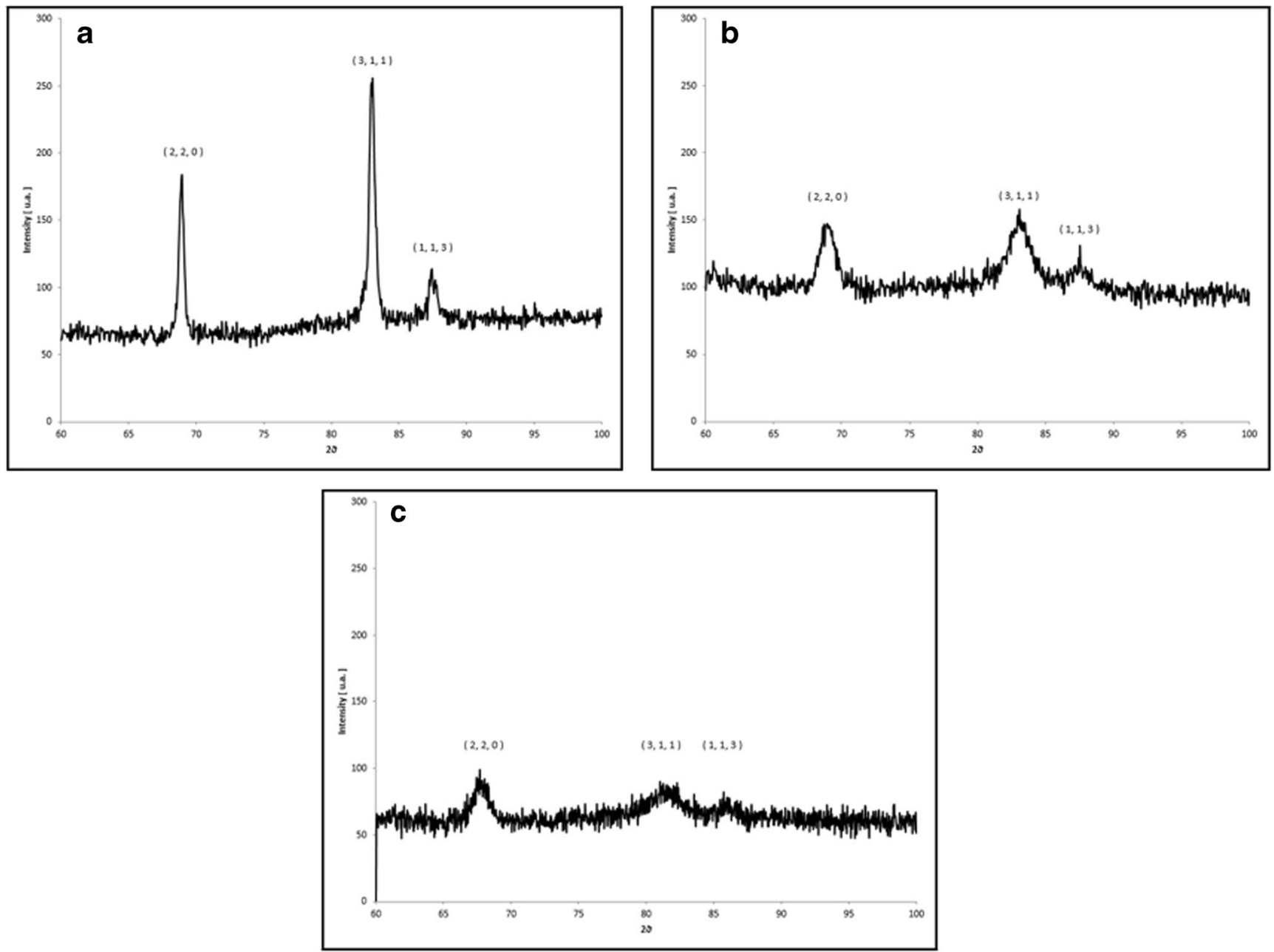

Fig. 8 X-ray diffraction patterns for the 10-Kt carat gold alloy (a), for the 9-Kt gold alloy (b), and for the 14-Kt gold alloy (c) 
Fig. 9 Potentiodynamic polarization test on the final work-hardened and the annealed wires obtained with the new optimized process for the 9-Kt gold alloy samples

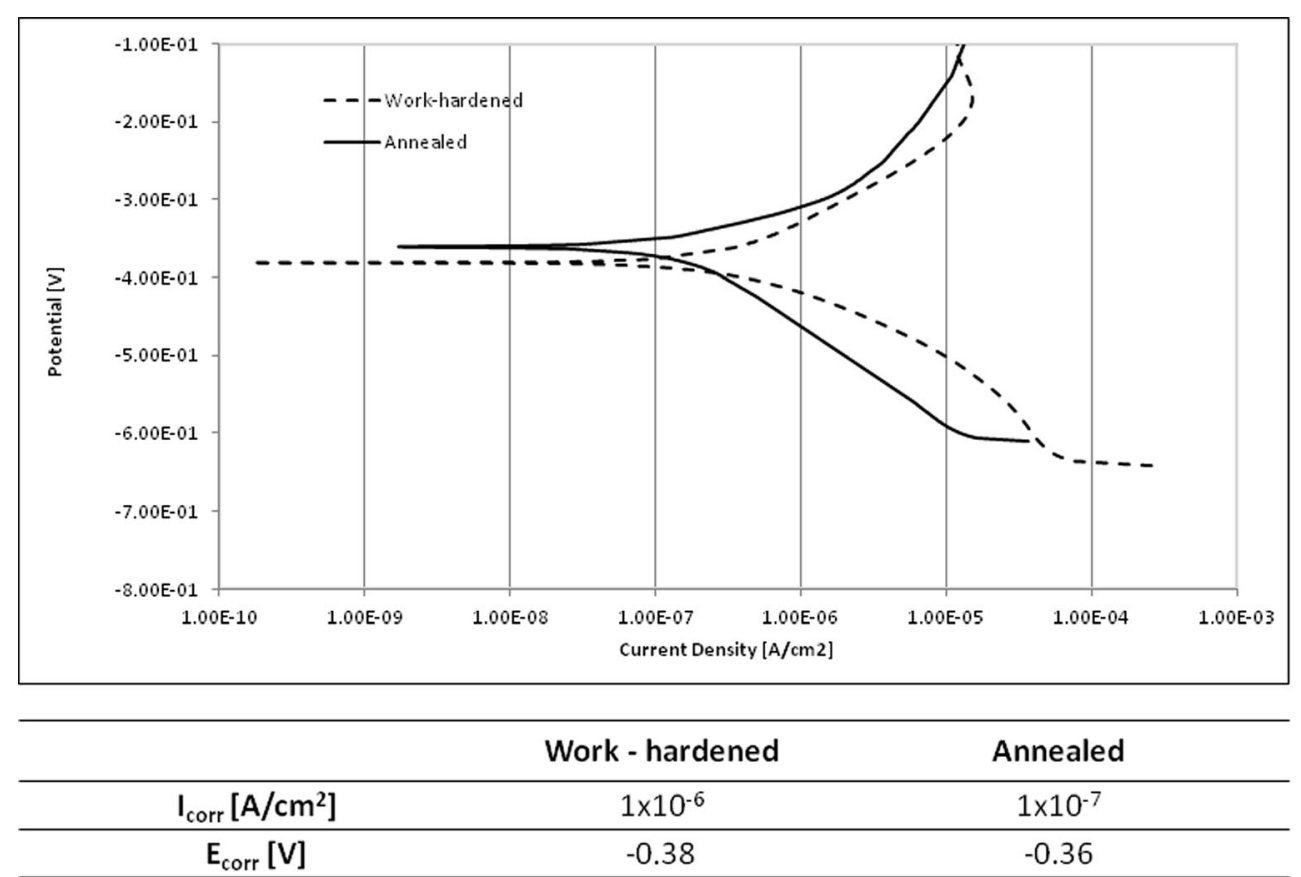

microstructure and the crystallization phenomena allowed to reduce the residual stresses.

In order to obtain information on the corrosion resistance of the different samples, anodic polarization tests in the solution that simulates human sweat were performed. Regarding the 9Kt samples, work-hardened and annealed samples were compared and the results are reported in Fig. 9; corrosion potentials and corrosion current densities $\left(I_{\text {corr }}\right)$ were also evaluated and reported. It has been observed that the two samples have the same corrosion potential but the corrosion current density of the annealed sample, which is directly linked with the corrosion rate by Faraday's law, is one order of magnitude lower. This observation can be connected to the decrease of the internal residual stresses during the annealing process, as previously discussed. For the 10-Kt alloy, samples were compared between the old and new production processes. The results of this comparison are presented in Fig. 10. A significant increase in the corrosion resistance can be observed with the new process, as the samples are characterized by a value of $I_{\text {corr }}$ which is approximately one order of magnitude lower,
Fig. 10 Potentiodynamic polarization test on the final annealed wires obtained with the two different processes performed for the 10-Kt gold alloy samples

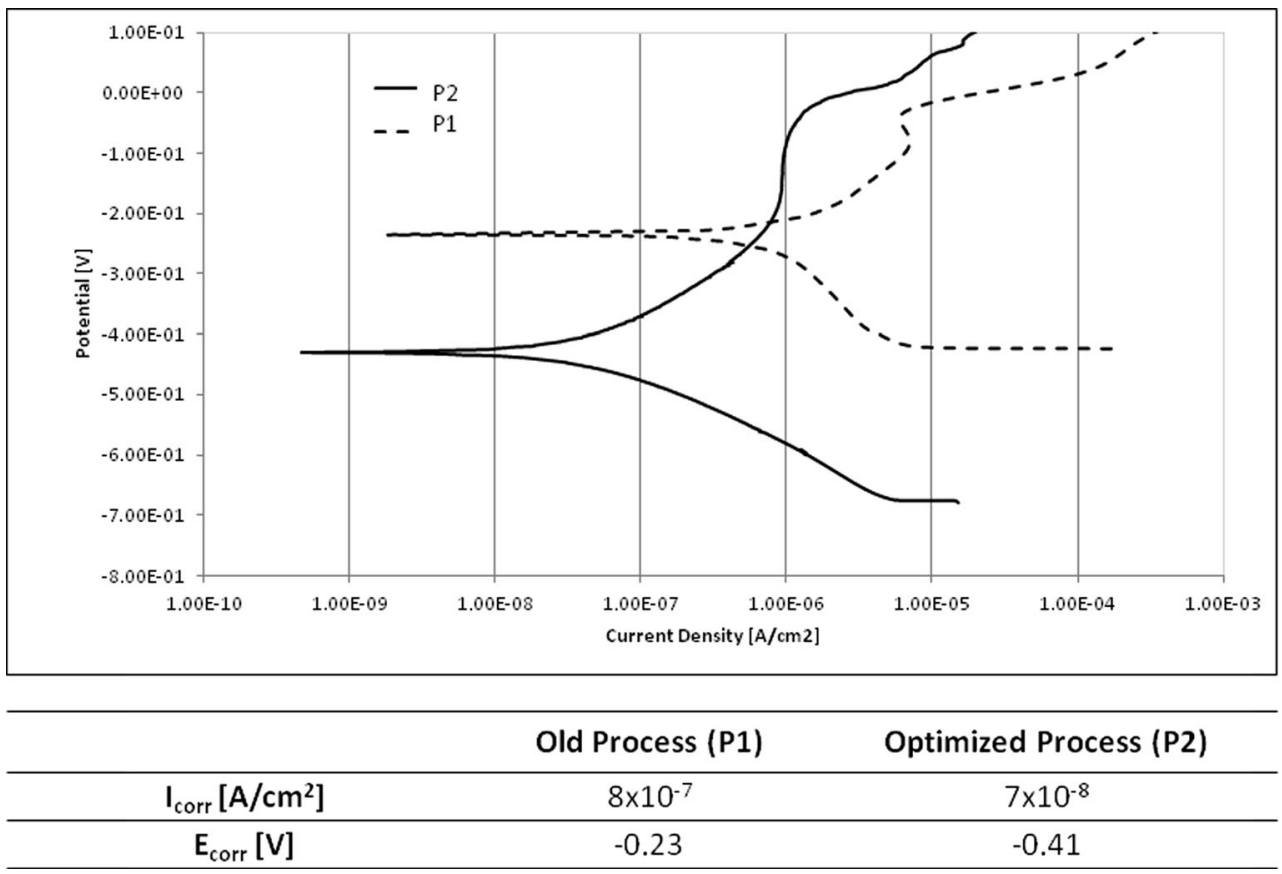


Fig. 11 Potentiodynamic polarization test on the final annealed wires obtained with the three different processes for the 14-Kt gold alloy samples

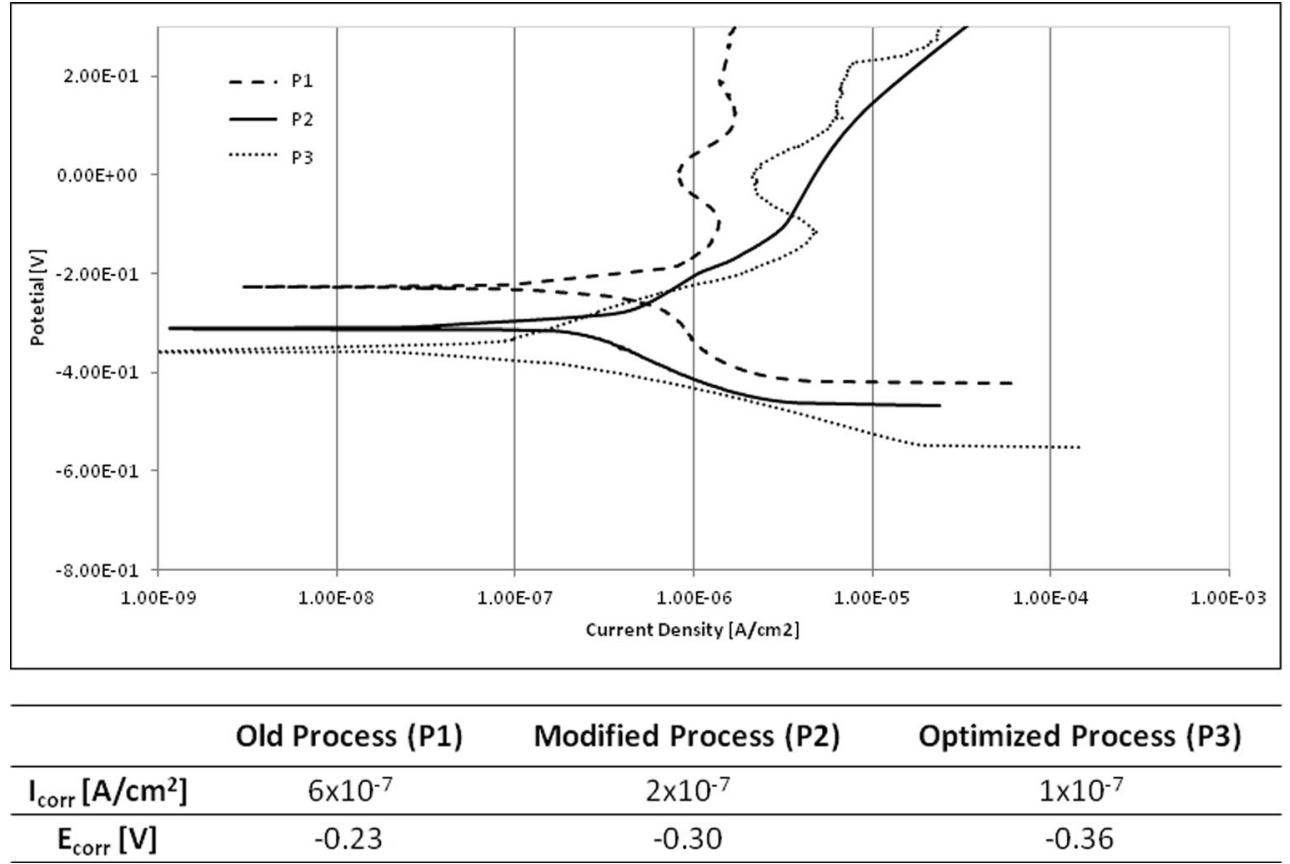

even though the corrosion potential is $0.2 \mathrm{~V}$ higher in the samples obtained with the old process. In the case of the 10Kt sample, the improved corrosion performances can be correlated with the decrease of the residual stresses in the samples obtained with the optimized process as previously discussed.

Samples of 14-Kt gold alloy obtained with the old and the new process were tested, and the results are reported in Fig. 11. In the case of 14-Kt samples, the samples obtained with the new process are characterized by a higher corrosion resistance due to the lower residual stresses previously reported, so that the corrosion current density decreases by one order of magnitude.

For all of the analyzed alloys, the corrosion tests performed on the different samples give evidence for an increase in the corrosion resistance (observed with the decrease of the corrosion current density) that can be correlated with the decrease of the internal residual stresses as shown by XRD analysis.

\section{Conclusion}

The presented optimization of the production steps of gold welding alloys allows one to have a consistent reproducibility of the material properties. A greater control of time and temperatures, during the melting and annealing processes, demonstrated the relevance of a proper control in the process parameters in order to obtain the desired results in terms of hardness. With an immediate cooling out of the furnace, there is insufficient time to create an orderly distribution of atoms in the microstructure; therefore, the annealing process generates a decrease in hardness. The gold wire can be further deformed because the recrystallization process restored the initial workability. The optimization of the whole process had not only an influence on the hardness but also produced an increase in the ductility of the gold alloys and in the microstructural homogeneity. The final grain size was also reduced. The tensile tests, performed on the final annealed wires, showed a smaller range of variability of the tensile curve, which is indicative of improved uniformity of properties along the skein of yarn produced. The optimization of the melting, rolling, and annealing processes for gold welding alloys wires allows for the reduction the residual stresses on the wires at the end of the production cycle, with improvements in mechanical properties, machinability, corrosion resistance during the emptying process, and a better finishing surface. The potentiodynamic polarization tests performed on the samples showed the importance of minimizing the residual stresses. It was shown that, independently of the carat of the gold alloys, the annealed microstructures, characterized by a lower level of residual stresses, have a better corrosion resistance. The corrosion current densities increased by one order of magnitude in the deformed samples, which implies an increase in the corrosion rate. Considering the same annealed state on samples produced either with the old process or with the optimized process, it is possible to say that the grain size and the homogeneity of the microstructure strongly influence the corrosion susceptibility of the gold alloys. A smaller grain size and a greater homogeneity, obtained with the optimized process, are preferred because these characteristics cause an increase in the corrosion resistance of the material. 
Acknowledgments The authors would like to acknowledge Filk S.p.A. for the financial support and for supplying the material and R\&D department of Progold S.p.A. for the support in metallographic preparation.

Open Access This article is distributed under the terms of the Creative Commons Attribution 4.0 International License (http:// creativecommons.org/licenses/by/4.0/), which permits unrestricted use, distribution, and reproduction in any medium, provided you give appropriate credit to the original author(s) and the source, provide a link to the Creative Commons license, and indicate if changes were made.

\section{References}

1. McDonald AS, Sistare GH (1978) The metallurgy of some carat gold alloys. Gold Bull 11(3):66-73

2. Pinasco MR, Stagno E (1979) Deformation and recrystallization of a jewellery white gold alloy. Gold Bull 12(2):53-57
3. Grimwade M (1992) The metallurgy of gold. Interdiscipl Sci Rev $17: 371-381$

4. Forty AJ (1981) Micromorphological studies of the corrosion of gold alloy. Gold Bull 14(1):25-35

5. Shreir LL (1976) Corrosion, vol 1. Newnes-Butterworths, London, p 167

6. Pickering HW, Wagner C (1967) J Electrochem Soc 114:698-706

7. Pickering HW (1967) In: Staehle RW, Forty AJ, van Rooyen D (eds) Fundamental aspects of stress corrosion cracking. N.A.C.E, Houston, pp 159-174

8. Yasuda K (1987) Age-hardening and related phase transformations in dental gold alloys. Gold Bull 20(4):90-103

9. Leinfelder KF, Taylor DF (1977) J Dent Res 56(3):335-345

10. Randak A, Trautes FW (1970) Werkst Korros 21(2):97

11. Elayaperumal K, De PK, Balachandra J (1972) Corrosion 28(7):269

12. Noyan IC, Cohen JB (1987) Residual stress - measurement by diffraction and interpretation. Materials research and engineering. Springer-Verlag, New York Inc

13. Residual stress measurement by X-ray diffraction (1971) SAE J784a. Society of Automotive Engineers Inc, NY 